\title{
Ueber die Erregung und Hemmung der Thätigkeit der nervösen Centralorgane.
}

\author{
Von \\ Dr. A. Freusberg, \\ Assistent am physiologischen Institut der Universität Strassburg.
}

Bei Gelegenheit der Anstellung von Versuchen, deren Resultate in einer im Archiv für Pharmakologie und experim. Pathologie demnächst erscheinenden Arbeit enthalten sind, und bei der Wiederholung und Abänderung älterer Reflexversuche an Frösehen, machte ich einige neue Beobachtungen, die mir einige Wichtigkeit und einen innern Zusammenhang zu haben schienen. Sie sollten in der vorliegenden Arbeit eine ausführliche Besprechung finden, nachdem ich vorher die aus ihnen gewonnene Ueberzeugung durch ausgedehnte Versuche erhärtet, geklärt und erweitert haben würde. Doch daran verhinderten mich die Umstände. Wegen bevorstehenden Abganges vom hiesigen physiologischen Institut musste ich mich darauf beschränken, die zerstreut gemachten Beobachtungen sorgfältig auf's Neue zu konstatiren, sie nach einigen Richtungen, doch nicht so weit, als ich wünschte, zu ergänzen und zu vervollständigen. So muss ich mich hier beschränken, nur eine Skizze zu geben von den beobachteten Thatsachen und von den aus ihnen zu ziehenden Schlüssen.

Ich ergreife diese Gelegenheit, um Herrn Professor Goltz beim Scheiden meinen tiefen Dank auszusprechen für die vielfache von ihm erhaltene Belehrung und für das Interesse, mit dem er meine in seinem Laboratorium ausgeführten Versuche begleitete und förderte.

I. Wie wir den Erregungsvorgang eines peripheren Nerven als denselben ansehen, mag er durch elektrische oder chemische oder mechanische oder irgend eine andere Reizung verursacht sein, und wie wir den Contraktionsvorgang beim Muskel als den gleichen ansehen, mag er durch Reizung des zugehörigen Nerven oder durch directe Applikation des Reizes auf den Muskel hervorgebracht sein, 
Ueber d. Erregung u. Hemmung d. Thätigkeit d. nerrösen Centralorgane. 175

gerade so haben wir in einem Centralorgan ganz denselben Zustand vor uns, wenn dasselbe das eine Mal durch Reizung sensibler Nerven, das andere Mal durch reizende Bestandtheile des Blutes in Thätigkeit versetzt wird. Weder die einzelne Ganglienzelle, noch eine Gruppe funktionell zusammengehöriger Ganglienzellen - ein Centrum - besitzt specifische Vorrichtungen zur Aufnahme des einen oder des andern Reizes. Demnach ist es nicht eine specifische Eigenthümlichkeit einzelner Centren, auf den einen oder den andern dieser Reize oder auf beide in Thätigkeit zu gerathen, sondern allen Theilen des Centralnervensystems, allen Centren kommt als eine $\mathrm{zu}$ ihrem Wesen gehörige Eigenschaft die Fähigkeit $\mathrm{zu}$, beiderlei Reize mit Thätigkeit zu beantworten. Die dem entgegenstehende Annahme, dass das Rückenmark vom Blute aus nicht in Erregung versetzt werde, habe ich in der erwähnten Arbeit (Ueber die Wirkung des Strychnins und Bemerkungen über die reflektorische Erregung der Nervencentren) widerlegt.

II. Die einzelnen Centren sind durch die gleichen Reize verschieden leicht erregbar. Gewisse Centren ("automatische ( Centren) sind ganz besonders empfindlich für die im Blute, d. $h$. in dessen Gehalt an Stoffwechselprodukten, vorhandene Reizursache. Eben wegen ihrer hohen Erregbarkeit bildet schon das normale Blut einen hinlänglichen Reiz, um sie in beständiger Thätigkeit zu erhalten. Ebenso ist jedes einzelne Centrum vorwiegend reizbar durch einzelne bestimmte sensible Nerven, und zwar durch diejenigen, welche ihre Endausbreitung in dem von ihm beherrschten Organ haben. Die schwache Reizung eines sensiblen Nerven ruft die Thätigkeit nur desjenigen Innervationscentrums hervor, mit welchem der gereizte Nerv in der hezeichneten nächsten physiologischen - und der Regel nach auch anatomischen - Verknüpfung steht. Auf leises Drücken einer Pfote bewegt der decapitirte Frosch nur das getroffene Bein; sanftes Reiben des Praeputium löst im isolirten Lendenmark beim Hunde reflektorisch Erektion aus; das Athmungscentrum ist für die Reizung des Lungenvagus so empfindlich, dass schon die durch die Ausdehnung der Lunge bewirkte Erregung desselben reflektorisch bei der Regulation der Athembewegungen eine Rolle spielt $\mathrm{u}$. s. w.

III. Wenn die Reizursache wächst, so breitet sich die Wirkung auch auf andere, als das zumeist empfängliche Centrum aus. Wie hat man sich diese centrale Verbreitung der Reizwirkung zu denken? 
Offenbar so: die einzelnen Centren und vor Allem die einander benachbarten sind unter sich in vielfacher nervöser Verbindung, sind anatomisch noch viel weniger als physiologisch genau zu umgrenzen. Wenn nun ein Centrum von einem Reiz getroffen wird, so bricht sich seine Erregung nicht bloss durch die nach Aussen offenstehende Pforte Bahn, wählt nicht bloss die zum peripheren Organ gehenden, etwa motorischen Nerven, sondern ergreift ganz ebenso die zu andern Centralapparaten führenden nervösen Verbindungsbahnen. Ja, man darf es vielleicht nicht einmal für ausgemacht halten, dass eine centrale Erregung die austretenden peripheren Nerven in dem Grade vor den intracentralen Bahnen bevorzugt, ersteren einen so viel stärkeren Impuls giebt als den letzteren, wie es aus dem Verhalten auf schwache Reize hervorzugehen scheint. Eine schwache sensible Reizung löst ja im Centralorgan die Innervation eines correspondirenden peripheren Nerven aus, ohne dass uns eine thätigkeitserregende Wirkung jenes Reizes auf die nicht unmittelbar betheiligten centralen Heerde ersichtlich wäre. Indess wenn eine starke Erregung eines Centrums sich intracentral auf andere Centren verbreitet, dann ist nicht abzusehen, warum dieselben intracentralen Bahnen nicht anch die schwächere Erregung eines Centrums benachbarter Centren signalisiren sollten. Dass diese nicht mit äusserlich sichtlicher Thätigkeit antworten, ist verständlich. Denn der Umsetzung einer einem Centralorgan zugeleiteten in eine von ihm ausgehende Nervenerregung stehen ja innerhalb des Centralorgans grössere Widerstände entgegen, als die Erregung eines peripheren Nerven an dessen Endorgan vorfindet.

Die centrale Ausbreitung der Reize ist ein neuer Grund für das oben Gesagte, dass nicht specifische Reflexübertragungsapparate existiren, die mit der anderweitig erregten Thätigkeit eines Centrums nichts zu schaffen haben, oder dass verschiedene Reize verschiedene, von einander unabhängige und einzeln für sich z. B. durch Vergiftungen veränderliche Angriffspunkte auf ein Centrum besitzen; vielmehr ergreift jeder Reiz das von ihm getroffene Centrum in allen seinen Theilen, selbst in seinen zu andern Centren führenden Verbindungsbahnen.

Die centrale Ausbreitung eines Reizes mit zunehmender Stärke hat nicht bloss Statt bei den sensiblen Reizen, sondern auch bei den vom Blute ausgehenden. Der physiologische Gehalt des Blutes an Stoffwechselprodukten erregt das Athmungscentrum zur physio- 
logischen Thätigkeit, d. h. es gerathen auf diesen Reiz bestimmte Muskeln in Thätigkeit. Nimmt der Reiz zu, besteht Dyspnoe, so erhalten nicht nur dieselben Muskeln stärkere, sondern es erbalten jetzt auch benachbarte Muskelgruppen Impulse, die auxiliären Respirationsmuskeln wirken mit. Mit weiter wachsendem Reiz ergreift die Erregung stets mehr Innervationscentren, immer weiter verbreitet sich die Thätigkeit, bis schliesslich bei der Erstickung die gesammte Körpermuskulatur in Krampf geräth.

In immer weiter greifendem Umfang ergreift hier der Reiz das Centralorgan und ergreift die verschiedenen Innervationsheerde desselben, je nach ihrer Empfänglichkeit für diesen Reiz, verschieden rasch zu dem Grade, dass Thätigkeit erfolgt.

Doch ist dieser Vorgang darin von der centralen Ausbreitung der Wirkung sensibler Reize verschieden, dass hier nicht bloss von den bereits bis zur Thätigkeitsauslösung gereizten Centren die übrigen indirekt Signale erhalten, dass vielmehr das venöse Blut auch für die letzteren, überhaupt für alle Theile des Centralorgans ein direkter Reiz ist, für den dieselben nur verschieden empfänglich sind.

Auch bei der Irradiation der durch starke sensible Reize geweckten Reflexe könnte man an eine direkte Reizung aller betheiligten Centren denken. Wenn z. B. der decapitirte Frosch auf Quetschen der Vorderbeine ausser Bewegungen der Vorderbeine auch solche der Hinterextremitäten macht, so könnte man glauben, sensible Bahnen führten vom Arm das Rückenmark hindurch direkt zu den Bewegungscentren der Hinterbeine. Wenn aber schon unsere Kenntniss der anatomischen Verhältnisse es höchst unwahrscheinlich scheinen lässt, dass jeder Punkt der Körperoberfläche mit jedem entfernt gelegenen Innervationscentrum in direkter nervöser Verbindung ohne dazwischengeschobene Ganglienzellen stehe, so spricht dagegen noch ein physiologischer Grund. Denn es wäre dann nicht verständlich, warum auf einen schwachen sensiblen Reiz nur der nächste, nicht aber die entfernteren Innervationsheerde in Thätigkeit gerathen. Dieses Verhalten ist aber sehr wohl verständlich, wenn, um bei dem angeführten Beispiel zu bleiben, alle sensiblen Nerven des Armes in der Nähe ihres Eintritts ins Rückenmark in Ganglienzellen ihr Ende finden, und wenn erst durch Vermittlung dieser Ganglienzellen die Reizung der Vorderpfote dem hintern entfernten Abschnitt des Rückenmarks zugeleitet wird. 
Denn diese Einschaltung von Ganglienzellen in die von dem Ort der Reizung zum reflectorisch erregten Innervationscentrum führende nervöse Verbindungsbahn bildet eine Hemmniss, die erst eine sehr beträchtliche Reizung durchbrechen kann.

IV. Hierin liegt auch die Erklärung für die schon angeführte Erscheinung, dass die Reizung eines sensiblen Nerven am leichtesten die Erregung des anatomisch entsprechenden centrifugalen, etwa motorischen Nerven hervorruft. Jenes Innervationscentrum wird eben durch einen Reiz am frühesten in Thätigkeit versetzt werden, mit welchem der gereizte sensible Nerv in directe Verbindung tritt; und verhältnissmässig unwirksam wird eine sensible Reizung für die diejenigen Innervationscentren sein, die erst indirect, von dem zunächst erregten Reflexcentrum her, in Miterregung versetzt werden.

Zugleich ist hier Folgendes hervorzuheben: Wenn ein Reiz, der auf die Hinterpfote angebracht, die Arme in Bewegung bringt, nicht direct in den centralen Innervationsheerd der Armmuskeln eintritt, wenn vielmehr dieser erst mittelbar, nämlich von dem erregten Innervationsheerd der Hinterextremitäten, also von einer weit entfernten Stelle des Centralnervensystems, den Anstoss zur Thätigkeit erhält, so überzeugt man sich von der inneren Uebereinstimmung einer vom Gehirn angeregten mit der reflectorischen Thätigkeit. Denn wie bei der Irradiation der Reflexe im Rückenmark von einem Centrum aus den andern Erregungen zuströmen, so schickt ein etwa durch einen Gesichtseindruck gereiztes Centrum im Gehirn den ausführenden Centren des Rückenmarks Impulse zu. Die Uebereinstimmung zwischen der vom Gehirn veranlassten und der irradiirtreflectorischen Thätigkeit eines Rückenmarkscentrums liegt darin, dass in beiden Fällen nicht ein unmittelbarer Reflex stattfindet, sondern das ausführende Centrum von andern mehr oder weniger entfernten centralen Heerden her seinen Impuls erhält. Doch besteht der tief einschneidende Unterschied, dass das Gehirn die Innervationsheerde des Rückenmarks einzeln und gesondert in Thätigkeit versetzt, dass aber z. B. bei der Irradiation eines Reflexes von einer Vorderextremität $\mathrm{zu}$ einer Hinterextremität stets das ganze dazwischenliegende Rückenmark, die Innervationscentren aller Extremitäten- und Rumpfnerven in Thätigkeit gerathen.

V. Die Thätigkeit der Centren des Rückenmarks richtet sich nur nach der Intensität, Zeitdauer und Ausbreitung, nicht nach der Qualität der ihnen zugehenden sensiblen Reize, wie es nach manchen 
Uober d. Erregung u. Hemmung d. Thätigkeit d. nervösen Centralorgane. 179

Reflexbewegungen des enthirnten Frosches scheinen könnte. So sind Wischbewegungen eines solchen Thieres nicht specifisch für die chemische Reizung; denn sie bleiben aus - gehen in hastigere Bewegungen über - bei starker chemischer Reizung und erfolgen anderseits auf schwache, anhaltende und genügend ausgebreitete mechanische Reize, z. B. Bürsten der Haut.

VI. Wenn mehrere Reizursachen, die einzeln für sich ein und dasselbe Innervationscentrum zur Thätigkeit anregen, gemeinschaftlich vorhanden sind, so summiren sich ihre $W$ irkungen.

Dieser Fall tritt ein:

a) wenn die sensiblen Nerven, die zu einem bestimmten Centrum führen - also in der Regel die über das von dem betreffenden Centrum beherrschte Organ sich ausbreitenden sensiblen Nerven gleiche oder verschiedenartige Reize gleichzeitig oder in rascher Folge erfahren.

Wenn man einen decapitirten Frosch in gleichen Zeiträumen (von mindestens 5 Minuten) mit der Pfote in schwach angesäuertes Wasser taucht, so wird derselbe die Pfote stets nach einer gleich langen Zeit (mit dem Metronom gemessen) zurückziehen; diese Reflexzeit bleibt sehr lange constant, wenn man nach jeder Reizung die Pfote von der Säure durch Abspülen reinigt. Taucht man mit oder ohne inzwischen erfolgendes Abspülen dieselbe Pfote zwei- oder mehrmal rasch hintereinander ein, so wird diese nachfolgende Reizung von einem um mehrere Metronomschläge früher erfolgenden Zurückziehen der Pfote beantwortet, als die erste und die nach längerer Pause wiederholte Reizung. Ebenso tritt die Reflexbewegung auf diesen chemischen Reiz erheblich früher ein, wenn dem Eintauchen in die Säure eine selbst schwache, kaum zur Reflexauslösung genügende mechanische Reizung unmittelbar vorhergeht. Erfolgt z. B. der Reflex constant nach 10 Metronomschlägen, so bedarf es deren nur 6, wenn vor dem Eintauchen eine schwache sensible Reizung voraufging (wobei natürlich der chemische Reiz erst dann applicirt werden darf, wenn die durch den mechanischen Reiz eventuell hervorgebrachte Bewegung abgelaufen), und nach einer Rahepause bedarf es wieder der ursprünglichen Zeit (10 Schläge) zum Wirksamwerden der chemischen Reizung. - Zieht ein Frosch beide Pfoten gleich rasch aus der Reizflüssigkeit, so vermag man mit einem Male eine gewaltige Differenz hervorzubringen, indem man durch die 
Schwimmhaut des einen Fusses eine Nadel steckt; die doppelt gereizte Pfote ist jetzt die rascher reagirende. - Beim Hund genügt oft beim freien Hinabhängenlassen des Hinterkörpers die dadurch veranlasste Spannung und Zerrung, um im isolirten Lendenmark Reflexbewegungen auszulösen ${ }^{1}$ ); bei Hunden, bei denen diese Erscheinung nicht auftrat, sah ich vielmal jene Bewegungen in beiden Beinen im unmittelbaren Anschluss an die Durchschneidung des einen $\mathrm{N}$. ischiadicus am Oberschenkel auftreten und wenige Tage lang bestehen; der Reiz der Nervendurchschneidung genügt für sich allein nicht zur Auslösung dieses Reflexes; denn derselbe fehlte bei allen andern Körperstellungen; aber gerade bei dem Herabhängen des Hinterkörpers summiren sich der durch die Zerrung der Extremitäten und der durch die frische Wunde gesetzte Reiz, um, was diese Reize einzeln nicht, vermögen, die Bewegungscentren der Hinterbeine zur Thätigkeit zu erregen.

Die Summirung der Wirkung schwacher gleichsinniger Reize ist im Grunde dieselbe Erscheinung, wie jene, dass eine starke Reizung kräftiger wirkt, als eine schwache Reizung desselben Nerven, sowie jene, dass rasch intermittirende Reize (Inductionsstrom, Kitzeln) wirksamer sind, als gleich starke Reize von momentaner Dauer oder von anhaltend gleichmässiger Einwirkung.

b) Eine Summirung der Reizwirkung tritt ferner ein, wenn eine sensible Reizung vermöge ihrer Heftigkeit oder vermöge ihrer Erstreckung auf ein grosses (Haut-) Gebiet das Centralorgan in weiter Ausbreitung, also wenn dieselbe eine Reihe einzelner Innervationsheerde zur Thätigkeit reizt, und wenn nun auf einen dieser Innervationsheerde ein neuer anderer Reiz wirkt.

Dieses Verhalten, so einfach und selbstverständlich es scheint, bedarf einer genaueren Besprechung. Wie stimmt dasselbe überein mit der Thatsache, dass die Reflexe durch gleichzeitig auf das Centralorgan einwirkende sensible Reize gehemmt werden? Ich hoffe zu zeigen, dass hier kein Widerspruch besteht, dass vielmehr ganz bestimmte Regeln sich feststellen lassen, nach denen in einem Falle die Wirkung eines sensiblen Reizes durch einen zweiten sensiblen Reiz unterdrückt, im andern Fall verstärkt wird.

Wund $t^{2}$ ) stellt die Regel auf: "Diejenigen sensorischen Ele-

1) Dieses Archiv IX S. 364 ff.

2) Physiologische Psychologie S. 175. 
Ueber d. Erregung u. Hemmung d. Thätigkeit d. nervösen Centralorgane. 181

mente, welche in gleicher Höhe und auf derselben Seite liegen, verstärken, wenn sie miterregt werden, den Reflexvorgang; allen andern kömmt in höherem oder geringerem Grade die hemmende Wirkung zu." Dies ist vollkommen zutreffend, so lange die beiden Reize an Stärke nicht zu sehr verschieden sind. Dass aber diése Regel keine allgemeine Gültigkeit hat, werden wir aus den sogleich beizubringenden Beweisen für den oben aufgestellten Satz und aus der spätern Besprechung der Reflexhemmung erkennen; wir werden zugleich sehen, dass nicht in dem anatomischen Verhältniss zweier gereizten sensiblen Nerven, sondern in der physiologischen Wirkung jedes einzelnen der gleichzeitigen Reize das Gesetz zu finden ist, nach weichem dieselben sich bald verstärken, bald hemmen.

Ich verdanke Herrn Dr. Ta rchan off die Kenntniss eines von ihm herrührenden, bisher nicht erklärten Versuches, der mich das oben Ausgesprochene zuerst vermuthen liess, und dessen Verfolgung diese Vermuthung zur Gewissheit, wie ich glaube, erhob. Dieser Versuch ${ }^{1}$ ), den Herr Tarchan of $f$ mir zeigte und zur Verfügung stellte, ist Folgender: Man bestimmt mit dem Metronom die Zeit, die vergeht, bis ein enthirnter Frosch die Pfote aus dem ungesäuerten Wasser zurückzieht. Dann wird der Vorderkörper (Kopf, Arme; Brust) in Eis eingepackt - am bequemsten zieht man dem Thier ein mit Eisstückchen gefülltes Beutelchen über den Kopf. Jetzt zieht der Frosch die von Neuem eingetauchte Pfote sehr viel früher und schneller aus der Flüssigkeit, macht auch ohne weitere Reizung einige Beinbewegungen. Sehr rasch nach der Entfernung des Eises ist der ursprüngliche Zustand wieder hergestellt, die Pfote verharrt während der anfänglichen grossen Zahl von Metronomschlägen in der Säure, bevor sie zurückgezogen wird. Eine neue Eiseinpackung reducirt die Reflexzeit von Neuem u. s. f. Während der Kältewirkung geschehen die Reflexbewegungen nicht blos früher, sondern auch heftiger als vor derselben.

Wie erklärt sich dieser Versuch? Mit einer allgemeinen Abkühlung des Thieres hat die Erscheinung nichts zu schaffen. Denn diese bewirkt ja im Gegentheil ein Trägerwerden des Organismus; und dann tritt ferner die reflexerhöhende Wirkung so rasch nach der Eisbepackung ein, dass von einer allgemeinen Abkühlung nicht

1) Veröffentlicht in den Bulletins de l'academie Impér. de sciences de St. Pétersbourg 1871 Février. 
die Rede sein kann. Ich halte folgende Erklärung für allein zutreffend. Der heftige Kältereiz, obwohl nur von einem beschränkten Hautgebiet dem Centralorgan zugeführt, breitet sich in diesem von den zunächst erregten Heerden aus auch auf die übrigen Centren aus und bringt sie zur Erregung. Wirklich macht die Erregung der Innervationscentren der Hinterextremitäten sich geltend in einigen zu Beginn der Kälteeinwirkung ohne einen neuen Reiz ausgeführten Beinbewegungen. Dass diese nachher ausbleiben, rührt nur von dem gleichmässigen, nicht intermittirenden Charakter des Reizes, schliesst nicht aus, dass nicht ihren centralen Innervationsheerden vom vordern unmittelbar gereizten Abschnitt des Rückenmarks her gewaltige Erregungen zuströmen. Gesellt sich jetzt zu diesem, für sich allein wenig wirksamen Impuls ein zweiter, von einem sensiblen Reiz der Pfote herrührender, dann summirt sich die Wirkung beider auf die Bewegungscentren, die Reflexbewegung erfolgt als eine verstärkte; und diese Verstärkung ist die hochgradigste: ein Frosch, bei dem der chemische schwache Reiz eine Zeitdauer von 15 Metronomschlägen braucht, um im Centralorgan eine Bewegung auszulösen, zieht unter jenem gleichzeitigen Einfluss des Kältereizes die Pfote schon beim zweiten Metronom zurück.

. Ich änderte den Versuch dahin ab, dass ich den Vorderkörper des Frosches in heissen Sand einpackte. Derselbe Erfolg trat ein. Die vom thermischen Reiz nicht betroffenen Beine machten einige Bewegungen, weil ihre Innervationscentren vom Vorderkörper her Impulse erhielten, und ein jetzt auf die Hinterpfote angebrachter schwacher chemischer Reiz wurde früher und stärker von Reflexbewegungen beantwortet, als vor (und nach) der thermischen Reizung des Vorderkörpers.

Sehr schlagend ist noch folgender Versuch: Ein decapitirter Frosch wird in stets gleichen Pausen chemisch gereizt. Aus der ganz schwachen Säure-Lösung $(1 / 3 \mathrm{pCt}$.) zieht er constant die Pfote nach 10 Metronomschlägen zurück. Wenn mit einem feineu Glasstäbchen - dessen mechanische Berührung mit der Haut keine Bewegung hervorruft - ein kleiner Tropfen einer $10 \mathrm{pCt}$. Schwefelsäurelösung auf die Rückenhaut in der Gegend der Arme gebracht wird, so beginnen ausser Armbewegungen nach 4 Metronomschlägen Bewegungen der Hinterbeine. Bei sofortigem Abspülen bringt diese heftige Reizung keine dauernde Veränderung der Erregbarkeit hervor, vielmehr sind nach der gewöhnlichen Ruhepause die genannten 
Ueber d. Erregung u. Hemmung d. Thätigkeit d. nervősen Centralorgane. 188

Reflexzeiten wieder gültig. Jetzt wird der Frosch gleichzeitig mit der Pfote in die schwache Säure getaucht und am Rücken, sei es auf derselben oder auf der entgegengesetzten Seite, mit der starken Säure gereizt: der Frosch beginnt jetzt schon beim ersten oder zweiten Metronomschlage die heftigsten, zappelnden Reflexbewegungen. Nach einer Pause bedarf es wieder 10, beziehungsweise 4 Metronomschläge, bis die beiden Reize, einzeln angewandt, wirksam werden, und der Versuch kann von Neuem angestellt, die Summirung der Wirkung von Neuem erziełt werden.

Das Wesentliche bei diesen Versuchen ist natürlich nicht, dass gleichzeitig mit dem auf den Hinterkörper einwirkenden schwachen Reiz ein starker Reiz sich gerade vom Vorderkörper her geltend mache. Die Wirkung ist vielmehr dann am stärksten, wenn der eine Reiz die ganze Körperoberfläche trifft und dem Centralorgan vọn allen Seiten zugeleitet wird. Das zeigt folgender Versuch.

Ein enthirnter Frosch zieht die Pfote nach 12 Metronomschlägen aus dem angesäuerten Wasser. Nun tauche ich nur den Vorderkörper in eine 4 procentige Kocbsalzlösung, spüle mit Wasser ab, um die Reflexbewegungen aufhören zu machen, und tauche sofort die Pfote wieder in die Säure. Sie wird nach 8 Metronomschlägen herausgezogen (bei stärkerer Concentration der Kochsalzlösung rascher). Nach einer Pause tauche ich den ganzen Frosch wieder in die Kochsalzlösung, spüle ihn $a b$ und tauche sofort wieder die Pfote in die Säure; sie wird nach zwei Metronomschlägen heftig daraus entfernt. Nachher ist die ursprüngliche Erregbarkeit wieder da, und lässt sich von Neuem durch das Kochsalzbad so hochgradig und sicher steigern.

Wir sehen: die Reflexbewegungen der Hinterextremitäten des decapitirten Frosches geschehen mit verstärkter Schnelligkeit und Intensität, wenn die Innervationscentren dieser Bewegungen durch einen auf beliebige Weise an beliebiger Stelle einwirkenden, das Centralorgan in weiter Ausdehnung ergreifenden Reiz einen gleichzeitigen Impuls zur Thätigkeit erfahren. Auch wenn diese Thätigkeit schon aufgehört, der Reiz schon beseitigt ist, so ist doch das Centralorgan noch nicht zur vollständigen Ruhe zurückgekehrt, und die nachklingende Erregung desselben summirt sich mit dem durch einen neuen, seitens der sensiblen Nerven des Beines dem Innervationscentrum zugeleiteten Reflexreiz zu verstärkter 'Thätigkeit.

c) Eine Summirung der Reizwirkung findet Statt, wenn das 
ganze Centralorgan von einem gemeinsamen, vom Blute ausgehenden Reize betroffen wird und nun auf dasselbe ein sensibler Reiz einwirkt. - Als ich eine Anzahl Warmblüter nach Durchschneidung des Rückenmarks am letzten Brustwirbel durch Einschneiden der Carotiden verbluten liess oder durch Compression der Trachea erstickte, stellte sich, im Gegensatz zu älteren Angaben, heraus, dass auch im Hinterkörper Bewegungen - wenn man will Krämpfe eintraten, dass also die Zersetzungsproducte des Stoffwechsels für die Centren des Rückenmarks in derselben Weise einen Reiz bilden, wie für die Medulla oblongata. Zugleich fand ich, dass bei Hunden noch vor dem Auftreten dieser Krämpfe und dass bei Kaninchen (bei denen die Krämpfe ganz unbedeutend ausfallen können) unter dem Einfluss jener vom Blute ausgehenden Reizung sensibler Reize weit leichter und energischer als zuvor Reflexe auslösten, und zwar sowohl Bewegungen der Beine und des Schwanzes, als Erektion, je nach der Stelle der sensiblen Reizung. Das entsprechende Verhalten constatirte ich auch bei decapitirten verblutenden Fröschen. Also wenn von Bestandtheilen des Blutes ein Centralorgan gereizt wird, wobei der Grad des Reizes noch zu gering sein darf, um für sich allein schon eine ersichtliche Thătigkeit $\mathrm{zu}$ bewirken, und wenn nun eine sensible Reizung hinzukömmt, so summirt sich ihre Wirkung zu einer verstärkten Reflexthätigkeit.

Ja, um dieses Verhalten zu zeigen; braucht man nicht einmal zur Erstickung und Verblutung zu greifen. Uspensky u. A., zuletzt ich, haben gezeigt, dass die Ueberarterialisation des Blutes, der Zustand der Apnoe, auch im unvergiftcten Thiere die Reflexthätigkeit hinanhält. Also schon im physiologischen Organismus muss zu einer sensiblen Reizung der geringe Reiz der stets im Blute vorhandenen Stoffwechselprodukte sich hinzugesellen, wenn eine Reflexthätigkeit erfolgen soll.

VII. Beachten wir wohl die Ergebnisse aus dem Gesagten. Es wirkt auf das Centralorgan irgend ein Reiz, durch sensible Nerven zugeführt oder durch Zustände des Blutes bedingt; dieser Reiz bewirkt entweder für sich allein eine bestimmte Thätigkeit, erregt ein bestimmtes Centrum, oder er lässt nach Auslösung der Thätigkeit das betreffende Centrum in einem gewissen Zustand der Erregung, von dem es erst nach einiger Zeit zum Ruhezustande zurückkehrt; oder er ist für sich allein zu schwach, um eine Thätigkeit auszulösen, was er aber bei einer etwas grösseren Stärke thun würde; 
Uober d. Erregung u. Hemmung d. Thătigkeit d. nervösen Centralorgane. 185

zu diesem Reiz gesellt sich ein zweiter, anderer Reiz, der gleichfalls dieselbe Thätigkeit erzeugen, dasselbe Innervationscentrum anzusprechen geeignet ist: das Resultat ist, dass eine stärkere Thätigkeit des Centrums erfolgt, als jedem einzelnen der Reize entspricht Also die Reizung eines Innervationscentrums steigert die Erregbarkeit desselben für jede neue Reizung desselben, welcher Art sie sei. Mit andern Worten: Die Steigerung der Erregbarkeit und der Zustand der Thätigkeit eines Centralorgans sind wesensgleiche, nur gradweise verschiedene Aenderungen seines innern Zustandes.

Von diesem Gesichtspunkte aus lassen sich mancherlei Erscheinungen neu erwägen. Die "automatischen " Centren der Med. oblongata haben von Hause aus, ohne dass wir den innern Grund wüssten, eine besonders hochgradige Empfindlichkeit für die von der venösen Beschaffenheit des Blutes ausgehenden Reize und auch für die sensiblen Reize, die ihnen von den zunächst beherrschten Organen der Athmung und Blutbewegung, also durch den $\mathrm{N}$. vagus, zugehen. Aber warum besitzen sie auch eine alle Centren so hoch überragende Empfindlichkeit für sensible Reize, die nicht ihnen unmittelbar überbracht werden, sondern weit entfernte Körpernerven treffen? Welchen Grund hat das Gesetz des dreiörtlichen Auftretens der Reflexe (Pflüger)? Warum beeinflusst ein Affekt schon das Herz, bevor sich irgend ein anderer Muskel regt? Das kommt eben daher, dass diese Centren in steter Thätigkeit, d. h. in der höchsten Potenz der Erregbarkeit sind. Dadurch bieten sie jedem Reiz einen wirksameren Angriffspunkt als andere Centren, darum beantworten sie jedes Signal, das ihnen von der Erregung eines andern Centrums zugeht, so rasch und leicht.

Eine einmal ausgeführte willkürliche oder reflektorische Thätigkeit findet die folgenden Male leichter Statt. Worauf beruht diese "Uebung". Warum fällt man in ein und denselben Lapsus linguae oder calami, hat man ihn einmal gemacht, in den nächsten Minuten so leicht zum wiederholten Male? Weil es noch andere $\mathrm{Zu}$ stände des Centralorgans giebt, als die grob ersichtlichen der Ruhe und Thätigkeit, weil vielmehr der eine in den andern durch $\mathrm{Zu}$ stände wachsender und abklingender Erregung übergeht. Dieser nachwirkende geringe Zustand von Erregung disponirt ein Centrum dahin, dass es auf einen ihm zugehenden Impuls leichter reagirt, durch Summirung der Reizvorgänge, als vorher; er bewirkt die an- 
geführte scheinbare Ablenkung eines Willensimpulses von seiner Bahn, indem ein durch die vorangegangene Thätigkeit erregbarer Ganglienheerd auf den Impuls eher reagirt, als das unerregbarere, dem der Impuls eigentlich galt.

Wer hat nicht schon an sich die unter Umständen recht unangenehme Erfahrung gemacht, dass ejn mechanischer Insult, ein Stoss oder Schlag, wenn er der Winterkälte ausgesetzte Hautstellen trifft, einen. ungewöhnlich heftigen, lange anhaltenden Schmerz hervorruft? Viele Schwerhörige sollen dann ein Gespräch ain Besten verstehen, wenn gerade Geräusche, z. B. Wagengerassel, stattfinden, Geräusche, die ein gesundes Ohr an der deutlichen Wahrnehmung der Stimme beeinträchtigen, die aber für sich allein nicht genügen, im kranken Ohr eine Wahrnehmung zu bewirken. Gewiss darf man bei solchen Beobachtungen gleichfalls an eine Summirung der Wirkung verschiedener dieselben Nerven treffender Reize denken.

Bei der Reizung des isolirten Lendenmarks bei Hunden mit Induktionsströmen sah ich, wenn kurz vorher der eine Ischiadicus durchschnitten war, beim jedesmaligen Einbrechen und Aufhören des Reizes nur das betreffende verwundete Bein in Zucknngen gerathen, während das gesunde bei derselben Stromstärke ruhig verharrte; es wirkten hier auf das Innervationscentrum des verwundeten Beines zwei Reize - der eine von der Peripherie her, der andere direkt - die jeder für sich nicht zur Thätigkeitsauslösung hinreichten.

Dass eine Summirung der Reizwirkungen nicht bloss in den centralen, sondern auch in den peripheren nervösen Vorrichtungen Platz greift, beweist die Beobachtung "Ueber die Reaktion gelähmter Gefässmuskeln«, die Hitzig veröffentlichte ${ }^{1}$ ).

Im Verbreitungsbezirk des $\mathrm{N}$. axillaris rief bei Lähmungen dieses Nerven dieselbe elektrische Behandlung, die an jeder gesunden Hautstelle eine Hautröthung erzeugte, im Gegentheil ein vollständiges Weiss- und Anämischwerden hervor, erst auf ganz ausserordentlich starke elektrische Reizung hin stellte sich Röthung, zugleich mit quaddelartigem circumscriptem Exanthem ein. Diese selbe Wirkung brachte aber auch ein, für sich allein angewandt von der ersteren Wirkung gefolgter Reiz, wie ein labiler constanter Strom hervor, wenn unmittelbar vorher die betreffende Hautparthie

1) Berl. klin. Wochenschr. 1874 Nr. 30. 
mit andern Reizen - stabilem Strom, mechanischem Insult, Bepinselung mit concentrirter Kochsalzlösung - Reizen, die für sich allein zur Erzeugung der Röthung nicht genügten, behandelt war.

VIII. Unter dem aufgestellten Gesichtspunkte rückt Manches in der Wirkungsweise toxischer Substanzen dem Verständniss näher. Ich stehe nicht an, zu glauben, dass die reflexerhöhende Wirkung des Strychnins darauf beruht, dass das ganze Centralorgan in allen seinen Theilen vom Strychnin gereizt wird. Und zwar. ist dieser durch Strychnin urzeugte Erregungszustand der centralen Heerde gar nicht einmal ein specifischer und andersartiger, als der durch sozusagen physiologische Reize hervorgebrachte. Denn

1) eine Steigerung der Erregbarkeit sahen wir auch auf die physiologischen Reize entstehen, und sie ist ebenso die Wirkung einer Menge anderer Gifte. Bei diesen wird blos die allgemein reflexerhöhende Wirkung oft verdunkelt durch die überwiegende Wirkung auf bestimmte einzelne Innervationscentren.

2) Ebenso entsteht der als für Strychnin so charakteristisch geltende Tetanus zuweilen auch durch die andern Reize. Nicht nur kann man durch eine hinlänglich starke electrische Reizung des Ischiadicus beim unvergifteten enthirnten Thier Tetanus hervorrufen, sondern ich sah eine Reihe kräftiger Winterfrösche - Sommerfrösche sterben ja oft unter spontanem Tetanus - nach lange fortgesetzter electrischer Reizung des Ischiadicus in einen, der Strychninvergiftung bis ins Kleinste ähnlichen Zustand fallen, der bis zu dem am nächsten Tage eintretenden Tode anhielt.

Bei jeder Berührung oder Erschütterung, und auch ohne solche brach ein heftiger Streckkrampf aus; auch jenes, dem Strychnintode voraufgehende Stadium blieb bei diesen unvergifteten Fröschen nicht aus, in welchem nur in grösseren Pausen mit oder ohne sensible Reizung ein leichter Krampfanfall sich einstellt, nach welchem die Erregbarkeit für einige Zeit ganz erloschen, das Thier scheintodt ist. - Ebenso merkwürdig und beweisend ist, was mir bei der schwachen Vergiftung enthirnter Frösche mit Digitalis und Nicotin je einmal begegnete, dass ein solcher Frosch einige Tage nach der Vergiftung bei Berührung in einen langen andauernden Tetanus fiel.

Also das Strychnin, in gehöriger Dosis, reizt das ganze Centralorgan in einer an sich nicht specifischen Weise, aber in so hohem Grade, dass unter dem Hinzutreten eines zweiten Reizes das Centralorgan mit der der heftigsten Erregung entsprechenden Thätigkeit, 
mit dem tetanischen Krampfanfall antwortet, einer Erregung und Thätigkeit, die die höchste Erschöpfung des Centralorgans nach sich führt. Dieser hinzutretende zweite Reiz nun wird gegeben einerseits von der venösen Beschaffenheit des Blutes; von der Summirung dieser beiden Reize rühren die ohne äussere Einwirkung auftretenden und auch nach der Durchschneidung des Rückenmarks im Hinterkörper nicht ausbleibenden Strychninkrämpfe. Dass bis zu einem gewissen Grade der im Gehalt des Blutes an physiologischen Stoffwechselproducten bestehende Reiz sich zu der Strychninwirkung auf das Centralorgan hinzugesellen muss, um die letztere als Thätigkeit in die Erscheinung treten zu lassen, beweist der Einfluss der künstlichen Respiration auf die Strychninkrämpfe. Andere Male sind es Reizungen sensibler Nerven, die zur Reizwirkung des Strychnins, auf das Centralorgan sich summirend, die gewaltigen Reflexkrämpfe auslösen.

Die erregbarkeitssteigernde Wirkung des Strychnins (und entsprechend wirkender Gifte) finde ich also darin begründet, dass dasselbe für sich allein schon jene Aenderung des innern molekularen Zustandes der Centralorgane bewirkt, die wir als Zustand der Reizung bezeichnen, und die wir in gleicher Weise durch andere genügend starke Nervenreize herbeiführen können. Ein hinzukommender Reiz wird diesen Zustand der Reizung verdoppeln, daher so excessiv gesteigerte Thätigkeiten bewirken. Der hauptsächlichste Unterschied zwischen der Wirkung des Strychnins und anderer Gifte, wie Picrotoxin, Nicotin und ähnliche, scheint mir der zu sein, dass das Strychnin nicht wie jene auf einzelne Centren eine überwiegende und massgebende Einwirkung entfaltet, sondern alle Centren des gesammten Centralorgans in einem ziemlich gleich hohen Grade afficirt.

Bei diesen Anschauungen wird es mir verständlich, warum mein Bemühen stets vergeblich sein musste, beim strychninisirten enthirnten Frosch einen durch Reizung der Hinterpfote hervorgerufenen Reflexkrampf durch einen an den Vorderpfoten angebrachten Reiz (und umgekehrt) zu unterdrücken, entsprechend der auf solche Weise zu erzielenden Hemmung der Reflexbewegungen des nichtvergifteten Thieres. Jeder sensible Reiz trifft eben auf ein Centrum, welches schon durch das Strychnin zur Thätigkeit angeregt ist, und so muss durch die Summirung dieser gleichsinnigen, aus zwei Quellen stammenden Erregung nicht eine Hemmung, sondern eine Verstärkung der Thätigkeit hervorgehen. 
Ueber d. Erregung u. Hemmung d. Thätigkeit d. nervösen Centralorgane. 189

In Rücksicht auf die Wirkung toxischer Substanzen muss ich den oben aufgestellten drei Kategorien von Summirung mehrerer Reize eine vierte hinzufügen. Nämlich eine Summirung der Wirkung tritt ein, wenn durch das Blut zwei Reizursachen einem Centralorgan zugeführt werden; wie dies vorhin für das Strychnin und die Producte der Gewebszersetzung besprochen wurde.

IX. Wir haben gleichzeitig auf ein Centralorgan wirkende Reize ihre Wirkung summiren gesehen. Wir wissen aber auch, dass gleichzeitig einwirkende Reize hemmend auf einander einwirken. Wann und unter welchen Bedingungen findet eine solche Hem $\mathrm{mu} \mathbf{n g}$ statt, und wie ist sie zu erklären?

Setschenow fand, dass, wenn man bei Fröschen, die der Hemisphären beraubt sind, die Lobi optici und Medulla oblongata electrisch oder chemisch reizt, die Reflexbewegungen der Thiere unterdrückt werden, und mindestens eine längere Zeit verstreicht zwischen der Application eines sensiblen Reizes und der Ausführung einer Bewegung. Er schloss daraus, dass in diesen Hirntheilen bestimmte Centren liegen mit der Aufgabe und Fähigkeit, die Reflexe zu hemmen. - Man hat später auch gefunden, dass beim Säugethier die electrische Reizung des Gehirns die Reflexe zu verlangsamen vermag. Da es aber hier nicht gelang, einzelne bestimmte Stellen ausfindig zu machen, denen diese Eigenschaft zukommt, so war hierdurch nichts weiter experimentell festgestellt, als was man aus der gewöhnlichsten Beobachtung, seit man Reflexe kennt, wusste, nämlich, dass das Gehirn einen hemmenden Einfluss auf das $\mathrm{Zu}$ standekommen von Reflexen auszuüben vermag.

Nach dieser Theorie, die die Steigerung der Reflexerregbarkeit durch Decapitation, als durch den Wegfall der Hemmungscentren sehr einfach erklärte, müssten sensible Reize dadurch reflexhemmend wirken, dass sie eben jene Hemmungscentren in Erregung versetzten.

Man glaubte sich zu der Annahme solcher Reflexhemmungscentren um so mehr berechtigt, weil man sie in Analogie bringen zu dürfen glaubte mit dem Hemmungscentrum der Herzbewegung, mit der Hemmungswirkung des Splanchnicus auf die Darmbewegungen. Wirklich hatte dieser Vergleich einige Berechtigung. Das Regulationscentrum des Herzens ist ja ein Hemmungscentrum nur in Bezug auf die automatischen Herzganglien, ist an und für sich ein Erregungscentrum, d. h. ertheilt dem Vagus Innervationen, 
die an sich nicht abweichen von den Impulsen, die andere Nerven von andern Centren erhalten. Erst die Eigenschaft der Herzganglien, die erhaltene Nervenerregung mit Verlangsamung ihrer eigenen Thätigkeitsauslösung zu beantworten, macht das Vaguscentrum zum Hemmungscentrum. Ebenso würde es mit den Reflexhemmungscentren Setschen ow's sein; die von ihnen ausgehenden activen Erregungen würden in den betroffenen Ganglienzellen die Thätigkeitsauslösung verlangsamen oder vollständig hemmen. Der Unterschied läge nur darin, dass das Vaguscentrum auf Ganglienzellen, die im peripheren Organ liegen, die Reflexhemmungscentren auf die Innervationsheerde des Rückenmarks, aber gleichwohl auf subordinirte Centren ihre Wirkung ausübten.

Diese Theorie, nach der die Reflexhemmung auf die Thätigkeit besonderer im Gehirn gelegener Hemmungscentren abgeleitet wurde, musste fallen gelassen und mindestens modificirt werden, als Herzen und Schiff nachwiesen, dass jede mechanische und chemische Reizung des Rückenmarks in seiner untern Partie eine Herabsetzung der Reflexvorgänge im vordern Theile des Markes hervorbringe, und dass ferner anch beim vollständig des Gehirns und des verlängerten Markes beraubten Frosch die Reizung sensibler Nerven die Reflexerregbarkeit für andere Reize unterdrücke. Sie glaubten eine Ueberreizung und Ermüdung des Centralorgans annehmen zu müssen, wogegen, wie Nothnagel mit Recht hervorhebt, der Umstand spricht, dass man auch bei ganz schwachen sensiblen Reizen und kurzdauernder Einwirkung eine Reflexhemmung beobachten kann: ich kann dieses letztere vollständig bestätigen. Ebensowenig befriedigend ist die Erweiterung, die Setschenow seiner Theorie gab, nämlich dass überall, im Centralorgan und auch im Rückenmark, besondere Reflexhemmungscentren angebracht seien. Solche Centren im Rückenmark kann man nicht mehr, wie die hypothetischen Hemmungscentren im Gehirn, als übergeordnete, sondern nur als nebengeordnete Apparate neben den Reflexübertragungscentren des Rückenmarks gelten lassen; damit büssen sie die jene stützende Analogie mit dem Herzregulationscentrum ein. Und wenn man erwägt, welche Complication man durch die Annahme solcher Centren, mögen sie im Gehirn oder im Rückenmark gesucht werden, in das Verständniss der Function und des Leitungsvorganges im Centralorgan einführt, anstatt das Verständniss zu erleichtern, die Anschauungen zu vereinfachen - denn jeder sen- 
sible Reiz müsste ja nicht nur ein entsprechendes Reflexübertragungs-, sondern auch alle Reflexhemmungscentren erregen können, und von den Gesetzen, nach denen bald die einen, bald die andern erregt werden, wüssten wir erst recht noch nichts! - so wird man an die Existenz solcher specifischen Hemmungscentren nicht glauben, so lange die Möglichkeit einer anschaulicheren und einfacheren Erklärung vorhanden ist.

Darum sind die von Goltz zuerst bei der Analyse des von ihm gefundenen Quackversuches gemachten Erläuterungen über die Reflexhemmung so viel ansprechender. Er führte als ein experimentelles Gesetz aus, „dass ein Centrum, welches einen bestimmten Reflexact vermittelt, an Erregbarkeit für diesen einbüsst, wenn es gleichzeitig von irgend welchen andern Nervenbahnen aus in Erregung versetzt wird"; er sieht also ab von specifischen Hemmungsvorrichtungen, verlegt den Grund der Hemmung in Zustandsänderungen der Reflexübertragungscentren selbst. Demgegenüber hält Nothnagel in seiner Arbeit süber den klonischen Krampf ( ${ }^{1}$ ) an den specifischen reflexhemmenden Apparaten im Rïckenmark fest, sich stiitzend auf neue Versuchsresultate. Ich werde hierauf sogleich näher eingehen, nachdem ich vorher, auf dem Boden der Goltz'schen Ausführungen weiterbauend, den Vorgang der Reflexhemmung besprochen haben werde.

$X$. Ich habe gesagt: "Diejenigen Reize verstärken gegenseitig ihre Wirkung auf ein bestimmtes Centrum, welche, jeder für sich, dessen Thätigkeit erzeugen «. Dem füge ich hinzu: Diejenigen Reize unterdrücken die Wirkungeines andern Reizes, welche für sich allein andere Centren zur Erregung und Thätigkeit bringen.

Sehr rein und klar stellt sich die Sache dar beim Goltz'schen Quackversuch. Das sanfte Streicheln der Rückenhaut eines des Grosshirns beraubten Frosches erweckt reflectorisch ein lautes schnarrendes Quacken; dieses bleibt aus, wenn man gleichzeitig die Hinterpfote z. B. durch Umschniürung, reizt, also einen Reiz anbringt, der eine Fortbewegung, bei solchen Fröschen allerdings meist nur einen Satz, hervorzurufen pflegt. Umgekehrt macht bei der Einzelwirkung dieser Reize das Thier auf das Streicheln des Rückens keine Ortsbewegung, giebt bei der Reizung der Pfote in der Regel

1) Virchow's Archiv XXXIV. 
keinen Laut von sich. Also es wirken zwei sensible Reize, die jeder für sich eine andere T'hätigkeit auslösen, ein anderes Centrum erregen. Die Folge ist, dass der schwächere Reiz, hier das Reiben der Rückenhaut, von der Auslösung seiner Wirkung abgehalten wird, während der stärkere Reiz, je nach seiner Stärke, die ihm zustehende Wirkung, hier die Bewegung der Hinterextremitäten, entweder hervorruft oder dafür zu schwach ist, resp. nach Hervorrufung der Thätigkeit zu schwach ist, sie nochmals zu erzeugen, aber hinlänglich stark nachwirkt, um die Reizung und Thätigkeit des andern Centrums unterdrückt zu erhalten.

Die intracentrale Verbindung der beiden hier in Betracht kommenden Stellen des Centralorgans, also des Knotenpunktes für die Innervation des Exspirations- und Stimmapparates und des Knotenpunktes für die Innervation der Hinterextremitäten ist aber keine einseitig auf Hemmungswirkungeu beschränkte. Denn beim unversebrten Thier kann der Stimmapparat durch sensible Reize, die den Hinterkörper treffen, in Thätigkeit versetzt werden (Schmerzensschrei), und diesen centralen Mechanismus und die nervösen Verbindungen, die die Auslösung des Stimmreflexes vom Hinterkörper aus ermöglichen, raubt die Exstirpation des Grosshirns offenbar nicht. Nach diesem Eingriff wird nun die mechanische Fähigkeit nicht mehr zur physiologischen Thätigkeit, und zwar deshalb, weil, wenn einmal ein den Hinterkörper treffender sensibler Reiz so stark ist, dass er auf die vorderen Theile des Centralorgans thätigkeitserregend übergreift, er dann in diesem zunächst andere Leistungen, vor Allem Ortsbewegungen, auslöst, was um so weniger auffallen kann, als auch der unversehrte Frosch überhaupt nicht leicht und sicher zum Schreien zu bringen ist.

Anderseits ist das Quacken beim des Grosshirns beraubten Frosch nicht ein für jede Reizung der Rückenhaut zutreffender ReHlex; es erfolgt nur bei dem sanften Reiz des Streichelns. Sowie man einen starken Reiz auf die Rückenhaut applicirt, gleichgültig ob in geringer oder weiter Ausbreitung, so geschehen statt des Quackens allgemeine Körperbewegungen, Bewegungen auch der Hinterbeine. Ferner werden wir von schwachen auf den Vorderkörper wirkenden Reizen eine Hemmung auf die Reflexe des Hinterkörpers stattfinden sehen.

Also ist die functionelle Verknüpfung der beiden genannten 
Ueber d Erregung u. Hemmung d. Thätigkeit d. nervösen Centralorgane. 193

Punkte des Centralorgans eine doppelsinnige, eine nach beiden Seiten erregende und hemmende.

Dazu kommt noch, dass das Reflexquacken nicht blos durch die Reizung der Hinterpfoten, sondern auch durch die Quetschung der Vorderpfoten oder der Rumpfhaut, und durch die starke mechanische oder chemische Reizung derselben Hautstelle, deren sanftes Reiben eben das Quacken erzeugt, unterdruckt und gehemmt wird, während diese Reize zugleich, wie gesagt, Extremitätenbewegungen hervorbringen. - Daraus lernen wir bezüglich des Quackversuches Folgendes:

1) Wir haben es nicht mit specifisch hemmenden Reizen oder mit einseitig hemmend wirkenden nervösen Léitungsbahnen, Verknüpfungen und Apparaten zu thun.

2) Das Verhältniss ist nicht ein solches, dass auf der einen Seite die Reizung sensibler Nerven, die weit von dem durch einen andern Reiz erregten Reflexapparat sich in's Rückenmark einsenken, hemmend auf dessen Reflexact wirkt, und dass auf der andern Seite die Reizung der in der gleichen Höhe und anatomischen Lage stehenden sensiblen Nerven ihre Reflexwirkung gegenseitig verstärkt; vielmehr sehen wir,

3) dass im Centralorgan diejenigen Reize hemmend auf die durch einen andern Reiz hervorgerufene Thätigkeit einwirken, welche, für sich allein, die Thätigkeit anderer Innervationscentren ansprechen.

Ich habe soeben angeführt, dass die schwache sensible Reizung der Haut des Vorderkörpers hemmend einwirkt auf die Reflexe der Hinterextremitäten. Tarchan off und ich ${ }^{1}$ ) haben gezeigt, dass ein Frosch die Pfote später aus der angesäuerten Flüssigkeit zieht, wenn man ihn mit den Fingern an der Brust festhält, als wenn man inn an einer durch den Oberkiefer gelegten Fadenschlinge frei hängen lässt. Eine gleiche Verminderung der Reflexbewegungen der Hinterbeine sah ich bei schwacher chemischer Reizung der Rückenhaut. Die Hemmung dieser Reflexe durch Umschnürung der Vorderpfoten, von L ew is s on zuerst beschrieben, ist bekannt. Ferner, wenn man einen Frosch an einem Hinterbein verwundet, so wird die durch gleich grosse mit Säure benetzte Papierstückchen ausgeführte Reizung der Bauchhaut auf derselben Seite später mit

1) Dieses Archiv IX. S. 387. 
Contraction der Bauchmuskeln beantwortet, als auf der andern Seite oder als vorher auf der gleichen Seite.

Wie verhält sich aber dem gegenüber das unter VI b Angegebene, dass ein auf den Vorderkörper wirkender sehr heftiger Reiz die Reflexbewegungen der Hinterextremitäten befördert? Wie erklärt sich diese entgegengesetzte Wirkung einer schwachen und starken Reizung derselben Hautstelle? Ich kann das nur darauf beziehen, dass eine solche starke Reizung das ganze Centralorgan und auch die Bewegungscentren der Hinterextremitäten zur Thätigkeit erregt und dadurch ihre Erregbarkeit steigert; dass hingegen ein schwächerer Reiz nur die zunächst betroffenen Centren im vorderen Rückenmarksabschnitt erregt, deren Erregung eben die Wirkung anderer Reize auf andere Centren beeinträchtigt.

Aus dem Gesagten ist zu schliessen, dass ein hemmend wirkender sensibler Reiz - etwa beim Quackversuch die Umschnürung oder Quetschung einer Pfote - auch seinerseits in seiner erregenden Wirkung beeinträchtigt und geschwächt wird durch eben die von ihm gehemmte Thätigkeit; der auf die Rückenhaut wirkende schwache Reiz wird durch die Reizung der Pfote an seiner Reflexwirkung vollständig gehindert; aber zugleich wirkt er seinerseits herabsetzend auf die durch diese Reizung der Pfote hervorgerufenen Reflexe, so dass diese schwächer ausfallen müssen. - In der That ist es mir bei allen Thieren stets so vorgekommen, als sei die Reflexhemmung immer eine gegenseitige, als schwäche der unterdrückte Reflexreiz die dem unterdrückenden Reiz zustehenden Reflexactionen.

XI. Ich wende mich jetzt zur Hemmung der im isolirten Lendenmark beim Hunde ausgelösten Reflexe ${ }^{1}$ ).

Die Zerrung, die beim senkrechten Herabhängen die Hinterextremitäten durch den $\mathrm{Zug}$ ihres eigenen Gewichts erfahren, genügt, um pendelnde Bewegungen auszulösen. Sie halten ein, wenn man den Schwanz kneift, während die starke Reizung des Schwanzes ihrerseits ausser Bewegungen seiner selbst auch Beinbewegungen bewirkt. Jene Pendelbewegungen der herabhängenden Hinterbeine hören ferner auf, - die Beine verharren wäbrend dieser Zeit still in bestimmter Stellung - wenn die Anfüllung der Harnblase einen Reiz auf die Blasennerven ausübt, der reflectorisch eine Harnentleerung bewirkt. Die natürliche Reizung der Blasennerven hemmt

1) Vergl. dieses Archiv IX. Reflexbewegungen beim Hunde. 
Ueber d. Erregung u. Hemmung d. Thätigkeit d. nervösen Centralorgane. 195

also die auf einen geringfügigen Reiz erfolgenden Beinbewegungen. Die gerade im Gang befindliche Blasencontraction wird aber zum Aufhören gebracht, wenn man eine Pfote quetscht, was seinerseits Reflexbewegungen der Beine verursacht - wie eben gesagt, schwächere Bewegungen, soweit dies taxirt werden kann, als dieselbe Reizung dann hervorbringt, wenn nicht der andere, unterdrückt werdende Reiz von der Blase her dem Centralorgan zugeht. Anderseits erzeugt ein starker rascher Druck auf die Blase (vielmehr Blasengegend) Reflexbewegungen der Beine. Endlich ist sicher auch die anatomische und mechanische Fähigkeit, $d . h$. die erforderlichen nervösen Verbindungsbahnen vorhanden, um durch Reizung der Beinnerven die Blasencontraction reflectorisch anzuregen; wenigstens ist diese bei manchen Hunden von der Haut der äussern Oberschenkelseite aus ebenso leicht anzuregen, wie durch Reiben des Dammes, und bei Fröschen habe ich Tags nach der. Decapitation oft die electrische Reizung das $\mathrm{N}$. ischiadicus und auch das Quetschen der Pfote von Harnentleerung begleitet gesehen. Dass beim Quetschen der Pfote diese Reflexbahn beim Hunde nicht ersichtlich betreten wird, beweist ebensowenig ihr Nichtvorhandensein, und ist ebenso in der überwiegenden Thätigkeit anderer Centren begründet, wie wir es beim Stimmreflex des Frosches gesehen, der trotz vorhandener anatomischer Möglichkeit durch die Reizung des Beines nicht zur Erscheinung gebracht wird. Man beachte überhaupt, wie alles beim Quackversuch und seiner Hemmung Gesagte auf das hier Besprochene übertragbar ist.

Das sanfte Reiben der Vorhaut ruft beim Hunde, auch weun das Riuckenmark durchschnitten ist, reflectorische Erection hervor, wobei die Beine aus ihren Pendelschwingungen, wie bei der Blasenentleerung, in eine bestimmte Ruhestellung übergehen, wobei also eine Hemmung auf die Bewegungscentren der Beine stattfindet. Die Erection schwindet, sobald man die Pfote oder den Schwanz kneift, was deren Bewegungen hervorruft. Hier kann man noch sagen: Die gereizten sensiblen Nerven senken sich in einer andern Höhe ins Lendenmark ein, daher die Hemmung. Aber wie stimmt zu solcher anatomischer Begründung der Hemmung die Thatsache, dass die durch sanftes Reiben der Vorhaut erzeugte Erection durch electrische Reizung und durch mechanische Quetschung der Vorhaut zum augenblicklichen Schwinden. gebracht wird? Hier haben wir 
wieder die entgegengesetzte Wirkung der schwachen und starken Reizung der gleichen Hautstelle.

Nun, jene starke Reizung der Vorhaut erweckt Reflexbewegungen der Beine, gerade wie das Quetschen der Pfote: daher wirkt sie, wie dieses, hemmend auf das Erectionscentrum.

Die Thatsache ist höchst merkwürdig. So gut wie der schwache Reiz, trifft doch auch der starke zunächst und zumeist das dem Vorgang der Erection vorstehende Centrum, und die Centren der Muskelbewegungen sind erst die an zweiter Stelle betroffenen und erregten; dennoch unterbleibt die Thätigkeit des ersteren zu Gunsten der Thätigkeit der Bewegungscentren. Warum bewirkt nicht die starke Reizung der Vorhaut gerade so, wie die schwache Reizung, umgekehrt Erection und Hemmung der Extremitätenbewegung? Ich möchte das damil in Zusammenhang bringen, dass die motorischen Centren im Rückenmark entschieden anatomisch (an Grösse und Ausbreitung) und functionell über die den vegetativen Vorgängen vorstehenden Centren überwiegen. Wenn einmal ein Reiz geeignet ist, sie zu erregen, dann gerathen auch gleich mehr Gang= lienzellen in Thätigkeit (um mich schematisch, aber doch vielleicht der Wirklichkeit nahe kommend, auszudrücken), als einem vegetativen Vorgang, z. B. der Erection überhaupt vorstehen, oder vielleicht kann man besser sagen: die Thätigkeitserregung der motorischen Centraltheile besteht in einem die der andern Centren übertreffenden Kraftverbrauch und Krafterzeugung. Das verschafft ihnen dann das Uebergewicht. In entsprechender Weise kann man sich, um darauf zurückzukommen, vorstellen, dass eine sensible Reizung der Pfote, die an sich geeignet wäre, beim hirnlosen Frosch reflectorisches Quacken, im isolirten Lendenmark des Hundes Blasencontraction anzuregen, zu gleicher Zeit den ganzen motorischen Centralapparat in eine so überwältigende Erregung versetzt, dass ihr gegenüber jene betreffenden Centren, wenn nun einmal das Centralorgan diese zweierlei Thätigkeiten nicht gleichzeitig zu leisten vermag, nicht zur Wirksamkeit gelangen können.

An den angezogenen Fall von Reflexhemmung könnte man leicht mit einigem Schein von Berechtigung anknüpfen, um, die Herzen'sche 'Theorie aufnehmend, die Reflexhemmung in einer Ueberreizung und Ermüdung beruhen zu lassen. Man könnte nämlich sagen: das Centrum der Erection im Lendenmark ist nach Ausweis des Zustandes seines peripheren Organs durch den geringen 
sensiblen Reiz des Reibens der Vorhaut in seine volle Thätigkeit und in den maximalen Erregungszustand versetzt worden. Darum muss eine jetzt ausgeführte starke Reizung derselben Hautstelle eine Ueberreizung desselben Centrums, und damit eine Erschlaffung bewirken. - In dieser Auffassung würde aber das Wort »Uebermüdung “ wieder einmal recht sich in seinem zweifelhaften Werthe einer Ausrede zeigen. Denn wie stimmt es zu ihrer Annahme, dass niemals die starke Reizung der Vorhaut die vorher nicht bestehende Erection erzeugt, und dass sofort nach dem Aufhören der starken Reizung das sanfte Reiben die Erection wieder hervorruft? Die Uebermüdung müsste doch die Reizung überdauern. Ja, oft stellt sich die durch die starke Reizung gehemmte Erection (und Blasencontraction) beim Aufhören des Reizes sofort von selbst, d. h. ohne neuen gelinden Reiz wieder ein. Wie will man das durch Uebermüdung, und wie will man es anders erklären, als dass die Wirkung und Nachwirkung des starken Reizes dann im Erectionscentrum zur Geltung kommt, sobald sie ihren erregenden Einfluss auf die Bewegungscentren eingebüsst?

Mit weit mehr Recht könnte man den Satz aufstellen, dass die "pathischen" Reize die "taktilen " an ihrer Wirkung hemmen. Indess diese Eintheilung der Reflexreize krankt daran, dass man im einzelnen Fall nicht weiss, ob ein Reiz ein pathischer oder taktiler ist. Immerhin trifft, mag man die pathischen Reize definiren als solche, welche im intakten Thier schmerzerregend wirken würden, oder als solche, deren Reflexwirkung nicht zur gereizten Stelle in bestimmter, ausschliesslicher Beziehung stehe (D a nilewsky), jene Aufstellung für manche Fälle von Reflexhemmung zu. Aber sie ist nicht umfassend genug. Einerseits hemmt der taktile Reiz des sanften Berührens grosser Hautflächen die durch geringe Reize hervorgerufenen Beinbewegungen beim Frosch und Hund; anderseits steigern, wie sub VI erörtert, auch entschieden pathische Reize die Reflexerregbarkeit.

Kurz, ich glaube nicht, dass das Gesetz der Reflexhemmung sich gegenwärtig genauer präcisiren lässt, als dahin, dass diejenigen Reize auf die von andern Reizen erzeugten Reflexe hemmend wirken, welche, andere Innervationscentren erregend, eine andere Thätigkeit des Organismus auslösen. Das Centralorgan wägt die ihm zugehenden Anregungen zu verschiedenen Thätigkeiten gleichsam ab, und lässt die Stärkedifferenz der beiden Reize in Wirksamkeit 
treten, so dass die Wirkung des stärkeren Reizes eine solche ist, als ob er allein mit der der Differenz der Reize gleichen Stärke auf das Centralorgan einwirkte. Bei gleichen Reizstärken ist dann die äussere Thätigkeit gleich Null.

XII. In dem Vorigen sahen wir die den Körperbewegungen vorstehenden Centren gleichsam in einem Oppositionsverhältniss stehen zu den Centren anderer, besonders vegetativer Funktionen. Die Thätigkeitserregung von Centren der einen Gruppe schloss die gleichzeitige Thätigkeit der andern Centren aus. Im gleichen Verhältniss sahen wir auch die Innervationscentren des Vorder- und des Hinterkörpers, speciell die Centren für die Vorder- und für die Hinterextremitäten beim decapitirten Frosche stehen. Während, wenn die letzteren durch einen Reiz in Erregung versetzt wurden, ein zweiter hinzutretender gleichfalls auf die Hinterextremitäten wirkender Reiz die Wirkung verstärkt, tritt eine Hemmung ein, wenn von zwei gleichzeitigen Reizen der eine nur die Bewegungscentren der Vorderextremitäten, der andere nur die Bewegungscentren der Hinterextremitäten erfasst. Hier steht überall der ganze centrale Innervationsapparat für die Hinterextremitäten den übrigen motorischen und den sonstigen Centren als Ganzes gegenüber. Wir werden jetzt gerade an diesem Innervationsapparat der Hinterextremitäten weitere Hemmungserscheinungen verfolgen. Auch durch sensible Reizung der Hinterextremitäten lassen sich Reflexbewegungen derselben unterdrücken. Widerspricht das nicht allem Vorgetragenen, und besonders dem schon erwähnten Umstand, dass die auf die Hinterextremitäten gleichzeitig wirkenden Reize ihre Reflexwirkung auf dieselben summiren?

Die Schwierigkeit schwindet, wenn wir dem Begriff und der Bedeutung eines Centrums näher treten. Ein Centrum ist die Summe der unter einander und mit der Nachbarschaft eng verbundenen Ganglienzellen, welche ein bestimmtes Organ oder einen Apparat innerviren, und mit ihm in nächster sensibler Verbindung stehen.

Man darf einem Centrum noch die weitere Eigenschaft zuschreiben, dass alle seine centralen Elemente stets zusammen erregt und thätig werden. Aber dieser Begriff des Centrums kann verschieden weit gefasst werden, dem entsprechend, dass die einzelnen Centren nicht anatomisch scharf zu umgrenzen und physiologisch zusammengehörige Funktionen nicht von einander zu trennen sind. So kann man beim Centrum der Athemmuskeln nur an die normal 
thätigen Athemmuskeln, aber auch an die Hülfsathemmuskeln resp. ihre innervirenden Ganglienzellen denken. Das Erectionscentrum begreift in sich eigentlich nur die Ganglienzellen, die ihre ausführenden Nerven zu den Schwellkörpern schicken; aber derselbe Reiz, der im isolirten Lendenmark des Hundes Erection auslöst, bewirkt gleichzeitig die Contraktion von Dammmuskeln. In derselben Weise kann man von einem Innervationscentrum der Hinterextremitäten als von einem Ganzen reden - wie es denn auch von hinlänglich starken Reizen in seiner Gesammtheit erregt wird -; ebenso gut kann man es als eine Gruppe einzelner Centren ansehen, bestehend aus den Centren der Beugung, Streckung, Ab- und Adduction denn alle diese Einzelbewegungen können für sich allein reflektorisch erzeugt werden - und besonders aus den Centren der rechten und linken Extremität.

Bei dieser Auffassung werden wir das oben Gesagte auch hier vollständig zutreffend finden.

Herzen fand, dass beim decapitirten Frosch die Reizung des Ischiadicus die Reflexerregbarkeit des andern Beins herabsetzt; dem gegenüber hob Setschenow hervor, dass bei starker Reizung die Reflexerregbarkeit des andern Beines gesteigert ist. Ich erkläre dies so: Wenn ein Reiz nur das rechtsseitige Bewegungscentrum zur Thätigkeit bringt, so beeinträchtigt diese die Wirkung eines geringeren anderen Reizes auf das linksseitige Centrum; wenn ein Reiz aber stark genug ist, beide Centren, auch das andersseitige Centrum zu erregen, so findet ein zweiter dieses treffende Reiz einen bessern, schon vorbereiteten Boden.

Dasselbe ergiebt sich aus den Versuchen, die ich in dieser Richtung anstellte.

Ich prüfte die Reflexzeiten bei Fröschen in Pausen von 5 Min. nach der T ür k'schen Methode. Die Reizflüssigkeit enthielt $1 / 3$ pCt. Schwefelsäure. Viele Frösche zogen beim Eintauchen beider Pfoten beide gleichzeitig zurück. Jetzt wurde nur eine Pfote eingetaucht, bei Beginn der Reflexbewegung sofort in Wasser abgespült, und dann sofort die andere Pfote eingetancht. Dabei wird stets die zuletzt eingetauchte Pfote später zurückgezogen, als die erste. Der erste Reiz hatte wegen seiner raschen Entfernung sich nicht auf das anderseitige Centrum erstrecken können, wirkte aber in dem gleichseitigen, zur Thätigkeit gebrachten Centrum noch nach, so dass die Reizung der andern Pfote und des andern Centrums in ihrer Wirk- 
samkeit eine Beeinträchtigung erfuhr. Wurden später die Pfoten in umgekehrter Reihenfolge gereizt, so wurde nur die vorhin verspätet reagirende Seite die rascher thätige. Die Differenz betrug 2-5 Metronomschläge (100 i. d. Min.). - Bei neuem gleichzeitigen Eintauchen beider Pfoten fand entweder gleichzeitiges oder auf der zuletzt gereizten Seite ein früheres Zurückziehen statt. War von vornherein die Erregbarkeit der Pfoten constant eine ungleiche, so liess sich derselbe Erfolg um so deutlicher machen. Das beim Eintauchen beider Pfoten regelmässig zuerst bewegte Bein, z. B. das linke, wurde erst nach einer grössern Zahl von Metronomschlägen überhaupt, und wurde insbesondere später als die rechte Pfote herausgezogen, wenn man die letztere zuerst einzeln eintauchte. - Ob nur eine, oder ob beide Pfoten zugleich eingetaucht werden, macht keinen constanten erheblichen Unterschied in der Reflexzeit. -

Wenn man die rechte Pfote eintaucht und die Säure nicht abspült, so geräth auch das linke Bein in Bewegung. Ist dieses wieder zur Ruhe gekommen, und taucht man es nun gleichfalls in die Flüssigkeit, so wird es nicht, wie in den vorigen Versuchen, nach längerer, sondern nach kürzerer Zeit herausgezogen, als das zuerst gereizte rechte Bein. Ebenso, wenn man gleichzeitig mit dem Eintauchen der einen Pfote auf die andere einen gehörig starken chemischen oder mechanischen Reiz wirken lässt, wird die eingetauchte rascher und heftiger bewegt, als jedem einzelnen der Reize entspricht; es tritt dann dieselbe Wirkung ein, als wenn auf das gleiche Bein zwei Reize wirken würden. Das Eintauchen in die Säure erregt eben jetzt keine neue Thätigkeit, kein anderes Centrum, sondern trifft ein schon ohnehin gereiztes Centrum: daher die Summirung, keine Hemmung der Wirkungen.

Auf die bemerkenswerthe bekannte Thatsache muss ich noch eingehen, dass der Frosch die Pfote nicht aus dem angesäuerten Wasser zieht, so lange man die andere Pfote mechanisch quetscht, und ganz gehörig quetscht; hier also scheinen die soeben gegebenen Thatsachen und Erörterungen ihre.Widerlegung zu finden. Wenn man die Sache genau ansieht, wird man statt der Widerlegung eine Stiitze für das Behauptete sehen. Nicht die gleichmässig, sondern die intermittirend wirkenden Reize sind die für die Nerven wirksamen. Quetscht man beim enthirnten Frosch eine Pfote, so macht er anfangs einige Bewegungen, dann hängt das nicht gereizte Bein schlaff 
Ueber d. Erregung u. Hemmung d. Thätigkeit d. nervösen Centralorgane. 201

herab, und ist in diesem Stadium auch durch andere, auf dasselbe direct einwirkende sensible Reize nicht zur Bewegung zu bringen; sowie man nun die gequetschte Pfote los lässt, erfolgen mächtige Bewegungen aller Extremitäten. Also der mechanische, noch so grobe Insult ist nur bei seinem plötzlichen Eintreten und bei seinem Aufhören ein starker, das Centralorgan in weiter Ausbreitung ergreifender Reiz; so lange er gleichmässig fortbesteht, ist er ein schwacher Reiz, der nur das nächste centrale Innervationsgebiet erregt, was dann die Unfähigkeit der andern Centren zu reflektorischer Erregung zur Folge hat.

Ein entsprechendes, hierher gehöriges Verhalten lässt sich auch für die Reflexbewegungen des Hundes aufinden. Die beim Herabhängen des Hinterkörpers durch die vom Muskelgefühl aufgefasste Zerrung erregten reflektorischen Pendelbewegungen der Beine hören, sobald man eine Pfote festhält, auch im andern Beine auf; kneift man aber die Pfote, so werden sie verstärkt, und zwar gleichfalls in beiden Beinen.

So klar zu Tage tretend und belehrend in mancher Beziehung die vom isolirten Lendenmark des Hundes ausgelösten Reflexe in ihrer Erregung und Hemmung sind, so stehen sie doch gerade in dem hier behandelten Punkte denen des Frosches an Deutlichkeit nach. Einmal fehlt es an einem Mittel, geringere Hemmungen und Beeinträchtigungen der Erregbarkeit so, wie es beim Frosch ausführbar ist, am Hunde genau zu messen. Sodann aber möchte ich glauben, dass bei den Hunden, die hier in Betracht kommen, etwas andere Verhältnisse vorliegen. Bei ihnen ist das Rückenmark schon vor längerer Zeit durchschnitten, mit den Fröschen experimentirte ich wenige Stunden nach der Decapitation. Auch wenn Frösche die fast unblutige Enthirnung durch Einstich hinter der Medulla oblongata längere Zeit überleben, so genügen in den späteren Tagen viel geringere Reize als im Anfang, um alle Extremitäten in Bewegung zu setzen. Zugleich geschehen die Bewegungen wieder mit einer gewissen Coordination, so dass geringe Ortsbewegungen, Ueberschlagen u. ähnl., wieder ermöglicht werden. Auf die entsprechende Veränderung möchte ich beim Hunde die geringere Deutlichkeit der Hemmung der Bewegungen der Beine durch auf sie einwirkende Reize beziehen, Entschieden vervollkommnen sich nach der Durchschneidung des Rückenmarks allmählich die motorischen Centren, zwar nicht an Stärke, aber an Feinheit ihrer Leistungen. 
Ausgeschlossen von der regulirenden Beeinflussung seitens des Gehirns erlangen die Bewegungscentren der Beine durch die oftmalige Uebung die Fähigkeit, die sie treffenden sensiblen Erregungen dahin zu verarbeiten, dass die Selhstregulirung der Beinbewegungen, die ich wahrscheinlich gemacht zu haben glaube ${ }^{1}$ ), und die auch schon im intacten Organismus besteht, einen höhern Grad der Ausbildung erlangt. So hat man es nicht mehr sowohl mit einzelnen lnnervationscentren einzelner Beinmuskeln, sondern mit dem zusammengehörigen Innervationssystem beider Beine zu thun, in welchem es durchaus nicht ausgeschlossen, sondern nur im Einzelnen trotz aller Wahrscheinlichkeit schwerer nachzuweisen ist, dass ein Reiz, indem er eine Leistung hervorbringt, eine andere in ihrem Zustandekommen hemmt.

XIII. Nunmehr kann ich zur Besprechung von Nothna gel's "reflexhemmenden Vorrichtungen“ im Rückenmark übergehen. Nothnagel reizte beim decapitirten Frosch den Ischiadicus elektrisch und fand Bewegungslosigkeit und Aufhören der Reflexerregbarkeit im andern Bein. Wenn er nach 24 Stunden wieder reizte, so machte das andere Bein nicht nur auf Berührung Reflexbewegung, sondern verfiel in Folge der Ischiadicusreizung selbst reflektorisch in heftige klonische Zuckungen. Er schliesst daraus, dass im Rückenmark reflexhemmende Vorrichtungen vorhanden sind, die sehr rasch und viel früher als die reflexübertragenden absterben.

Setschenow beschreibt schon früher bei der Anstellung solcher Versuche andere Erfolge; ebenso kam ich bei ihrer Wiedcrholung zu andern Resultaten. Eine solche Verschiedenheit scheint mir nur daraus erklärlich, dass die Versuchsresultate nicht von unfehlbarer Constanz sind - und das sind sie hier wegen der verschiedenen Erregbarkeit verschiedener Frösche - und dass jedem Beobachter, sobald er nach den ersten Versuchen sich ein Urtheil zu bilden beginnt, andere Umstände unwillkürlich als die Hauptsache sich aufdrängen.

Ich habe Nothnagel's Beschreibung vielfach zutreffend gefunden, sah aber so viel Abweichendes und Hinzuzufügendes, dass dieses mir nicht als Ausnahme erscheinen kann. . Das Verhalten, welchem ich oft genug begegnete, um es als das typische anzusehen, ist Folgendes: Wenn man beim Frosche $1 / 2-2$ Stunden nach

1) Dieses Archiv IX. S. $375 \mathrm{ff}$. 
Ueber d. Erregung u. Hemmung d. Thätigkcit d. nervösen Centralorgane. 203

der Decapitation einen Ischiadicus mit dem Inductionsstrom reizt, so tritt bei einer gewissen, im Allgemeinen schwachen, jedoch für verschiedene Frösche verschiedenen Stromstärke eine Beugung beider Beine ein; gleich darauf erlöscht die Wirksamkeit des Reizes auf die andere Seite, das intakte Bein hängt wieder schlaff herab und ist in diesem Stadium schwer oder gar nicht durch mechanische Reizung zu einer Reflexbewegung zu bringen; manchmal fehlt die voraufgängige Beugung, oder geht eine durch einen voraufgehenden Reiz veranlasste Beugung bei Beginn der schwachen electrischen Reizung der andern Seite sofort zurück. - Lässt man jetzt sofort durch Verschieben der sekundären Rolle einen stärkeren - mittelstarken bis starken - Strom einbrechen, so fährt das soeben unthätige intalkte Bein sogleich in Beugestellung, macht nach einiger Zeit einige langsame mittlere Streckungen und Beugungen, dann einige gewaltsame klonische Zuckungen, die übergehen in tetanische Streckung. Wenn jetzt der Strom aufhört, besteht oft der Krampf noch eine Weile fort; der Frosch behält nach diesen Vorgängen und nach einem vorübergehenden Zustand der Erschöpfung eine erhöhte Erregbarkeit, die, wenn nach einigen Stunden dasselbe Verfahren wieder eingeleitet wird, sich so steigert, dass er ganz das Bild eines strychninisirten Frosches bis zum Tode bietet (siehe oben). Aber auch ohne dass man es zu dieser äussersten Thätigkeit hat kommen lassen, besitzt der Frosch, wenn nach einigen Stunden oder am andern Tage der Versuch wiederholt wird, meist eine gesteigerte Erregbarkeit, so dass geringere Stromstärken hinreichen, um die angegebenen Reflexerscheinungen hervorzubringen. Allerdings fehlten einzelne Male am ersten Tage die klonischen Zuckungen; sie fehlten aber ebenso oft am zweiten Tage; beide Fälle, auf Untauglichkeit der Frösche beruhend, sind zu vernachlässigen. Die Hauptsache ist, dass unmittelbar nacheinander, und zuweilen sogar in mehrmaliger Wiederholung die schwächere Ischiadicus-Reizung eine Reflexhemmung, die stärkere Reizung eine Reflexthätigkeit der andern Seite hervorrief, dass also in einem verschieden raschen $\mathbf{A b}$ sterben reflexhemmender und übertragender Apparate die Erklärung nicht liegen kann.

Die verschiedenen Abweichungen will ich nicht aufführen, und nur noch erwähnen, dass zuweilen Frösche, die auf méchanische Reizung einer Pfote sehr schwache Reflexe machen, nach einer mittelstarken Reizung des Ischiadicus stärkere allgemeine Reflex- 
erregbarkeit besitzen; ferner, dass bei manchen Fröschen am ersten oder zweiten Versuchstage die Reflexhemmung durch IschiadicusReizung nur undeutlich oder gar nicht auftritt. Bei solchen Fröschen kann man aber, wenn man sie nach der Türk'schen Methode prüft, vom Vorderkörper her noch eine beträchtliche Herabsetzung der Reflexbewegungen der Hinterbeine constatiren. Also hat man es auch hier nicht mit dem Absterben reflexhemmender Apparate zu thun; vielleicht darf ich mich auf das oben Aufgestellte beziehen, dass die den Beinbewegungen vorstehenden Centren durch die reflektorische Uebung mehr den Charakter eines einheitlichen Centrums erlangen, in ihrer Zusammengehörigkeit gestärkt werden.

Stellen wir die Resultate, auf die es hier ankommt, zusammen, so finden wir in diesen Versuchen dasselbe Verhalten wieder, wie wir es bei den andern Versucheu sahen. Beim Eintritt einer schwachen Reizung, und, was ich noch nachträglich erwähnen muss, und auch N othnag el erwähnt, noch stärker bei ihrem plötzlichen Aufhören macht das andere Bein Reflexbewegungen; die Wirkung erstreckt sich also über den Ursprungsheerd des gereizten Ischiadicus hinaus auf andere Bewegungscentren. So lange der Reiz andauert, bleibt nur dasselbe Bein gebeugt, das andere unversehrte hängt bewegungslos herab und ist auch durch sensible Reizung nicht zu Reflexbewegungen zu bringen, weil eben das Centrum des gereizten Ischiadicus thätig und zwar allein thätig ist. - Wirkt aber ein stärkerer Strom auf den Ischiadicus, so erstreckt sich seine Wirkung weithin im Centralorgan. Zuerst macht das andere Bein einige schwache Bewegungen, dann arbeiten die Arm- und Rumpfmuskeln, und schliesslich erfolgen die heftigsten Entladungen seitens des gesunden Beines; zugleich ist seine Thätigkeit, weil sein centraler Heerd ohnehin schon erregt wird, jetzt durch einen neuen, sich hinzugesellenden Reiz zu verstärken, seine Reflexerregbarkeit ist erhöht.

Die Annahme besonderer reflexhemmender Vorrichtungen im Rückenmark ist demnach nur unter der gezwungenen, unerwiesenen Voraussetzung möglich, dass eine schwache Reizung sie erregt und eine starke Reizung sie ausschaltet. Mir scheinen die Thatsachen viel besser verständlich aus der merkwürdigen Eigenschaft des Centralorgans, die es nicht gestattet, dass verschiedene seiner einzelnen Gebiete gleichzeitig durch verschiedene Ursachen thätig werden.

XIV. In der gleichen Weise möchte ich die, der Aufstellung 
besonderer reflexhemmender Apparate in der Medulla oblongata und den Lobis opticis (Setschenow) zu Grunde liegenden Versuchsresultate deuten. Ein auf jene Stellen des Centralorgans allein einwirkender Reiz setzt die Erregbarkeit aller andern Stellen zur Thätigkeit herab, nicht in Folge einer spezifischen Eigenschaft jener gereizten Heerde, sondern dem a $11 \mathrm{~g}$ e mein für das Centralorgan geltenden Gesetz zufolge. Ich habe an anderer Stelle hervorgehoben, dass die heftige Reizung der automatischen Centren, z. B. bei der Erstickung und Verblutung im Stande ist, die reflektorische Thätigkeit und Erregbarkeit der übrigen centralen Heerde zu hemmen, so lange dieselbe Reizursache die übrigen Centren in sehr viel geringerem Grade erregt, und möchte hier den Umstand, dass der der Med. obl. beraubte Frosch eine höhere Reflexerregbarkeit aufweist, als vor ihrer Exstirpation beziehen auf die stete vom Blute aus angeregte Thätigkeitserregung der automatischen Centren.

Ferner möchte ich glauben, dass diese selbe Erscheinung, nämlich dass jede, auf irgend eine Weise erzeugte Reizung einer Stelle des Centralorgans die Thätigkeit aller andern Stellen desselben beeinträchtigt, eine Rolle spielt bei der nach der Durchschneidung des Rückenmarks bestehenden Unerregbarkeit desselben für sensible Reize. Beim Frosche dauert nach jenem Eingriff dieses Stadium nur ganz kurze Zeit, beim Hunde, vielleicht auf die entzündliche Reizung der Wunde zu beziehen, mehrere Tage. Unzweifelhaft wirken aber hier auch andere Verhältnisse mit, wie daraus hervorgeht, dass bei einem decapitirten Frosch die Abschneidung eines weitern Stückes vom Centralorgan die Reflexerregbarkeit der Hinterextremitäten nicht wieder heribsetzt; danach scheint in der That, beim Frosch wenigstens, jene erste vorübergehende Unerregbarkeit die Folge der durch die Durchschneidung bewirkten heftigen, krampfhaften, eine Ermüdung zurücklassenden Thätigkeit. Doch ist auch zu beachten, dass die Entfernung des Gehirns und verlängerten Markes für das Bewegungscentrum der Hinterbeine ein schwerer wiegender Eingriff sein muss, als die Wegnahme eines entfernten Stückes Rückenmark; bedeutet doch erstere die Ausschaltung übergeordneter, letzteres die Ausschaltung nebengeordneter Apparate. Beim Hunde dauert, wie gesagt, jenes Stadium geringer Erregbarkeit längere Zeit, obwohl im Moment der Rückenmarksdurchschneidung durchaus nicht so heftige, krampfhafte Bewegungen des Hinterkörpers eintreten, als beim Frosch und Kaninchen. 
XV. Es sind höchst merkwürdige Thatsachen, die im Vorstehenden erörtert sind. Die Reizung der ganzen Körperoberfläche erhöht die Erregbarkeit des Centralorgans. Die schwache sensible Reizung der Haut des Vorderkörpers erzeugt in diesem Thätigkeitsäusserungen (Quacken, Armbewegungen) und beeinträchtigt die Reflexbewegungen der Hinterextremitäten. Hinwiederum bringt eine starke Reizung des Vorderkörpers ausser Bewegungen der Vorderund Hinterextremitäten auch eine erhöhte Reflexerregbarkeit der letzteren hervor. Die mässige Reizung eines Beines steigert seine Erregbarkeit für andere auf dasselbe wirkende Reize, während sie die Reflexerregbarkeit des andern Beines herabsetzt. Die starke Reizung des einen Beines erzeugt mit Reflexbewegungen des andern Beines zugleich eine gesteigerte Erregbarkeit desselben für hinzukommende andere Reize. Anhaltende Reize mittlerer Stärke wirken während ihrer Dauer nur auf die Innervationscentren desselben Beines, bringen aber bei ihrem plötzlichen Beginn und Aufhören Reflexbewegungen auch des andern Beines zu Stande.

Man könnte das durch allerlei Hypothesen sich veranschaulichen und etwa so sich ausdrücken, dass das centrale Verbreitungsund Erregungsgebiet eines sensiblen Reizes eine positive Zustandsänderung erleidet, - erhöhte Erregbarkeit zeigt -, der gegenüber alle übrigen, vom Reiz nicht erregten Theile des Centralorgans sich negativ verhalten - in einen Zustand verringerter oder aufgehobener Erregbarkeit gerathen; und dass die plötzliche Entstehung und Ausgleichung dieser Zustandsänderung beim Eintritt und Verschwinden des Reizes eine allgemeine Thätigkeitserregung des ganzen Centralorgans mit sich führt. Aber damit ist gar nichts anzufangen, weil, wie wir gesehen, die starke Reizung derselben Hautstellen, deren taktile Reizung reflektorisch Quacken oder Erection hervorruft, diese Vorgänge unterdrückt und während ihrer Einwirkung nicht von Neuem erwecken lässt. Ich sehe darum von jeder Erklärung als vorderhand uninöglich ab und halte darum nicht minder für erwiesen und allgemein maassgebend die Eigenschaft des Rückenmarks, dass jede Leistung irgend einer Thätigkeit die Erregung einer andern Thätigkeit beeinträchtigt, während sie die Erregung der gleichen Thätigkeit erleichtert; mit andern Worten, dass jede Reizung beliebiger Centren diese erregbarer macht und zugleich die unbetheiligten Centren mehr oder weniger vollkommen unfähig macht, auf ihnen zugehende andere Reize in Thätigkeit zu gerathen. 
Ueber đ. Erregung u. Hemmung d. Thätigkeit d. nervösen Centralorgane. 207

Die Thätigkeitsleistung sowohl als die Erregbarkeit eines Centrums resultirt also aus der Summe der ihm zugehenden und früher zugegangenen Reize, vermindert um die Beeinflussung seitens der jeweilig durch andere Reize erzengten Erregung anderer Centren.

Welches der letzte Grund und das innere Geschehen der Reflexhemmung ist, entzieht sich der Untersuchung. Aber ich glaube, dass diese merkwürdige, in der ganzen Physiologie des Rückenmarks vielleicht merkwürdigste Erscheinung der richtigen Würdigung und Beurtheilung näher geführt werden kann durch einen Seitenblick auf die Physiologie des Gehirns. Denn hier zeigt sich, dass die Thätigkeitshemmung durchaus kein dem Rückenmark allein angehöriger absonderlicher Vorgang ist, dass vielmehr dem gesammten Centralnervensystem und allen seinen Theilen die Unfähigkeit zukommt, zwei Herren zu dienen, zwei Erregungsursachen gleichzeitig mit vollkommenen Leistungen zu beantworten.

In dem Gebahren der Thiere, etwa der Hunde, lassen sich, wenn man nur darauf achtet, oft mit überraschender Deutlichkeit die Vorgänge der Reflexerregung und -Hemmung wiedererkennen. Ein Hund sieht seines gleichen; der Reflex besteht darin, dass er sich zu diesem gesellt. Der Ruf seines Herrn ist ein anderer Reflexreiz; dieser kann im Widerstreit der Eindrücke zu Gunsten jenes erstern Reflexreizes unterliegen; er wird aber, wenn er durch Gewöhnung und Erziehung der wirksamere ist und ein für ihn durch Uebung sehr empfindliches Centralorgan trifft, denselben von seiner Wirkung abhalten und seine eigene Wirkung wird eintreten, nämlich- dass der Hund seinem Herm folgt. Dies allergewöhnlichste Beispiel möge genügen; die Belege zu erschöpfen, müsste man das ganze Thun und Treben der Thiere vorführen. - Wie aber beim Menschen? Man achte einmal darauf, wie viele Menschen es giebt, die in der einfachsten, ganz mechanisch ablaufenden Hantirung, zu der sie, wie man sagt, ihren Kopf gar nicht brauchen, innehalten, sobald sie nur angeredet werden; ich meine nicht ein absichtliches Innehalten, z. B. zum Zweck der Entfernung eines Geräusches, sondern das ganz instinctive, gedankenlose Aufhören der Arbeit. Was ist es anders, als eine Hemmung einer Thätigkeit durch einen, eine andere Hirnthätigkeit erweckenden Eindruck? Man achte darauf, wie ein Kind, bei dem noch nicht rein mechanisch, sondern unter der Aufmerksamkeit und Controle des Gehirns die Beine zum Gehen bewegt werden, sofort unsicher geht und stolpert, wenn irgend 
208 Dr. A. Freusberg: Erreg. u. Hermm. d. Thätigk, d. nerv. Centralorgane.

ein Gegenstand seine Aufmerksamkeit fesselt. Freilich, wenn die Fähigkeiten und Leistungen des Gehirns durch Schulung verbessert und veredelt sind, dann ist in seiner Thätigkeit wie die reflektorische Natur ihrer Erregung, so die reflektorische Hemmung - durch gegenwärtige oder von früher her nachwirkende Eindrücke - im Einzelnen immer schwerer zu verfolgen. Aber auch beim entwickeltsten Gehirn giebt es eine Grenze, über der die Thätigkeitshemmung wieder klar zu Tage tritt. Niemand kann geistige und körperliche Arbeit gleichzeitig verbinden, ohne dass die eine oder die andere Abbruch erleidet. Niemand kann in zweierlei Gedänkenreihen sich gleichzeitig vertiefen, und die geistige Concentration auf einen Gegenstand vermindert die Empfänglichkeit für äussere Eindrücke. Eine Wahrnehmung, die im Begriff ist, uns zu einer Thätigkeit zu veranlassen, wird von dieser Wirkung abgehalten, wenn ein anderer Eindruck oder die Erinnerung an einen solchen auftaucht, der für sich allein eine andere Thätigkeit, die nicht einmal die entgegengesetzte zu sein braucht, zu bewirken im Stande ist. Und wie viel mag von den Aeusserungen der Angst und des Schreckens im Grunde auf denselben Vorgängen beruhen, wie die Hemmung der Reflexe im isolirten Rückenmark.

So spielt die Thätigkeitshemmung durch Reize nicht blos im Rückenmark in Bezug auf die Reflexbewegungen, sondern in den Leistungen des ganzen Centralnervensystems und seiner Theile nach allen Richtungen eine wichtige Rolle. Und so erkennen wir in der Mechanik des Rückenmarks die des Gehirns, in der Mechanik des Gehirns die des Rückenmarks wieder.

Ueber das Auftreten von Gallenfarbstoff im Harn.

Von

\section{F. Hoppe-seyler.}

In Band IX S. 566 dieses Archivs hat Herr $\mathrm{Naunyn}$ in Königsberg đurch einige Behauptungen, die er auf keine Versuche stützt, versucht, die Resultate zu verdächtigen, welche $v$. T a r c $h$ a n of $f$ in mehren Versuchen an Hunden in meinem Institute erhalten 